\title{
Strategies for Industrial Development Layout in China within the Constraints of Environmental Carrying Capacity
}

\author{
Hao Jiming ${ }^{1,2}$, Wang Jinnan ${ }^{3}$, Jiang Hongqiang ${ }^{3}$, Liu Nianlei ${ }^{3}$ \\ 1. School of Environment, Tsinghua University, Beijing 100084, China \\ 2. State Environmental Protection Key Laboratory of Sources and Control of Air Pollution Complex, Beijing 100084, China \\ 3. Chinese Academy of Environmental Planning, Beijing 100012, China
}

\begin{abstract}
Under China's goal of ecological civilization construction, research into strategies for industrial development layout within the constraints of the environmental carrying capacity has become increasingly important. Based on China's atmospheric and water carrying capacities, its water resources, and the positions of its main functional zones, this study proposes strategies for the green layout of industries across China and energy resources for key regional industries under the constraints of the nationwide environmental carrying capacity and the carrying capacities of the Beijing-Tianjin-Hebei (Jingjinji) region, five northwestern provinces and autonomous regions, and other key areas. These strategies provide scientific guidance for industrial layout planning and the achievement of a successful combination of industrial development and environmental protection.
\end{abstract}

Keywords: environmental carrying capacity; industrial development layout; strategic tasks

\section{Introduction}

China's economy and society have been rapidly developing since the implementation of the reform and opening-up policy, but this extensive development, which has been characterized by high resource consumption and high pollution emissions, has resulted in significant problems, including environmental pollution and ecological damage. Environmental resources form an increasingly restrictive bottleneck for economic and social development, thereby seriously affecting China's modernization process. China is now in a period of transitioning from realizing growth at the cost of environmental resources. Under the Chinese Communist Party and the government's proposal to incorporate ecological civilization construction into the "fivein-one" overall layout of socialism with Chinese characteristics, strengthening restrictive top-down governance capacity and governance system construction is urgently needed; exploring the economic development model within the constraints of environmental carrying capacity is an effective and reasonable approach. Scientific understanding of environmental carrying capacity has gradually become the foundation for central and local governments to determine regional strategies and policies for development and layout planning [1].

Environmental carrying capacity is a scientific concept that measures relationships between human social and economic activities and the natural environment; it is an important basis for humans to measure sustainable development and management decisions and is an adequate method for quantitative evaluation of industrial area layout [2,3]. Environmental carrying capacity-based industrial area layout considers giving full play to the

Received date: June 20, 2017; Revised date: July 25, 2017

Corresponding author: Hao Jiming, Chinese Academy of Engineering, Academician. Major research fields include clean energy utilization and atmospheric pollution prevention and control. E-mail: hjm-den@tsinghua.edu.cn.

Funding program: CAE Advisory Project "Several Strategic Issues on Eco-Civilization Construction (Phase II)" (2015-ZD-16); Project of National Natural Science Foundation of China "Innovative Study on Management Mechanism of Regional Air Quality" (71433007)

Chinese version: Strategic Study of CAE 2017, 19 (4): 020-026

Cited item: Hao Jiming et al. Strategies for Industrial Development Layout in China within the Constraints of Environmental Carrying Capacity. Strategic Study of CAE, https://doi.org/10.15302/J-SSCAE-2017.04.004 
integration capacity and synergistic effects of various resource factors in the region. It pursues the optimal form and practices for industrial area layout according to regional characteristics and is of important practical significance for regional industrial orientation and industrial area layout [4,5]. However, there are few research achievements in this respect; most research has only proposed to guide industrial layout with the concept of environmental carrying capacity and has failed to quantitatively estimate the threshold of environmental carrying capacity and provide environmental carrying capacity-based industrial area layout direction, and specific controlling countermeasures. Therefore, this study evaluates the environmental carrying capacity of the whole country, the Beijing-Tianjin-Hebei (Jingjinji) region, five northwestern provinces, and Inner Mongolia in terms of atmospheric environmental capacity, water environmental capacity, and water resource carrying capacity, among others. In combination with planning the main functional area, this study proposes strategic controlling countermeasures for "green" industrial development layout within the constraints of environmental carrying capacity.

\section{Methods and main results of environmental carrying capacity evaluation}

\subsection{Atmospheric environmental carrying capacity}

Based on the third-generation air quality model WRF-CAMx and the nationwide atmospheric pollutant emissions inventory, an iterative algorithm [6] of atmospheric environmental capacity with environmental quality as a constraint was designed, and the simulated calculations of maximum allowable emissions, namely the atmospheric environmental capacity, of $\mathrm{SO}_{2}, \mathrm{NO}_{x}$, primary $\mathrm{PM}_{2.5}$, and VOCs for the whole country, Jingjinji region, five northwestern provinces, and Inner Mongolia were conducted with the objective of the $\mathrm{PM}_{2.5}$ average annual concentrations of all provinces throughout China meeting ambient air quality standards (GB3095-2012). The ratio between atmospheric pollutant emissions and environmental capacity (overload rate) was calculated to measure the atmospheric environmental carrying capacity status. It should be noted that the data were affected by factors such as the complexity of data limitations, model calculation processes, and uncertainty of parameter selection; thus, the calculation results of atmospheric environmental capacity given herein were subject to uncertainties, and there is a need to quantitatively study such uncertainties in future studies.

The calculation results are shown in Table 1, from which it is clear that various atmospheric pollutants in the entire country and in the key regions are under serious overload conditions, with overload rates of above $150 \%$. Among the various pollution indicators, the primary $\mathrm{PM}_{2.5}$ and $\mathrm{NO}_{x}$ were subject to the most serious overloads; the overload rates of nationwide primary $\mathrm{PM}_{2.5}$ and $\mathrm{NO}_{x}$ were $259 \%$ and $217 \%$, respectively. If the atmospheric environment were not overloaded, the reduction in various atmospheric pollutants of all regions relative to 2013 would be between $30 \%$ and $75 \%$.

\subsection{Water environmental carrying capacity}

Based on the water function zoning and water quality objectives specified in the Water Function Zoning of Important Rivers and Lakes Throughout the Country (2011-2030), the accounting model of water environmental capacity was established [7], chemical oxygen demand (COD) and ammonia nitrogen water environmental capacity of all water functional areas throughout

Table 1. Atmospheric environmental capacity of pollutants and overload conditions.

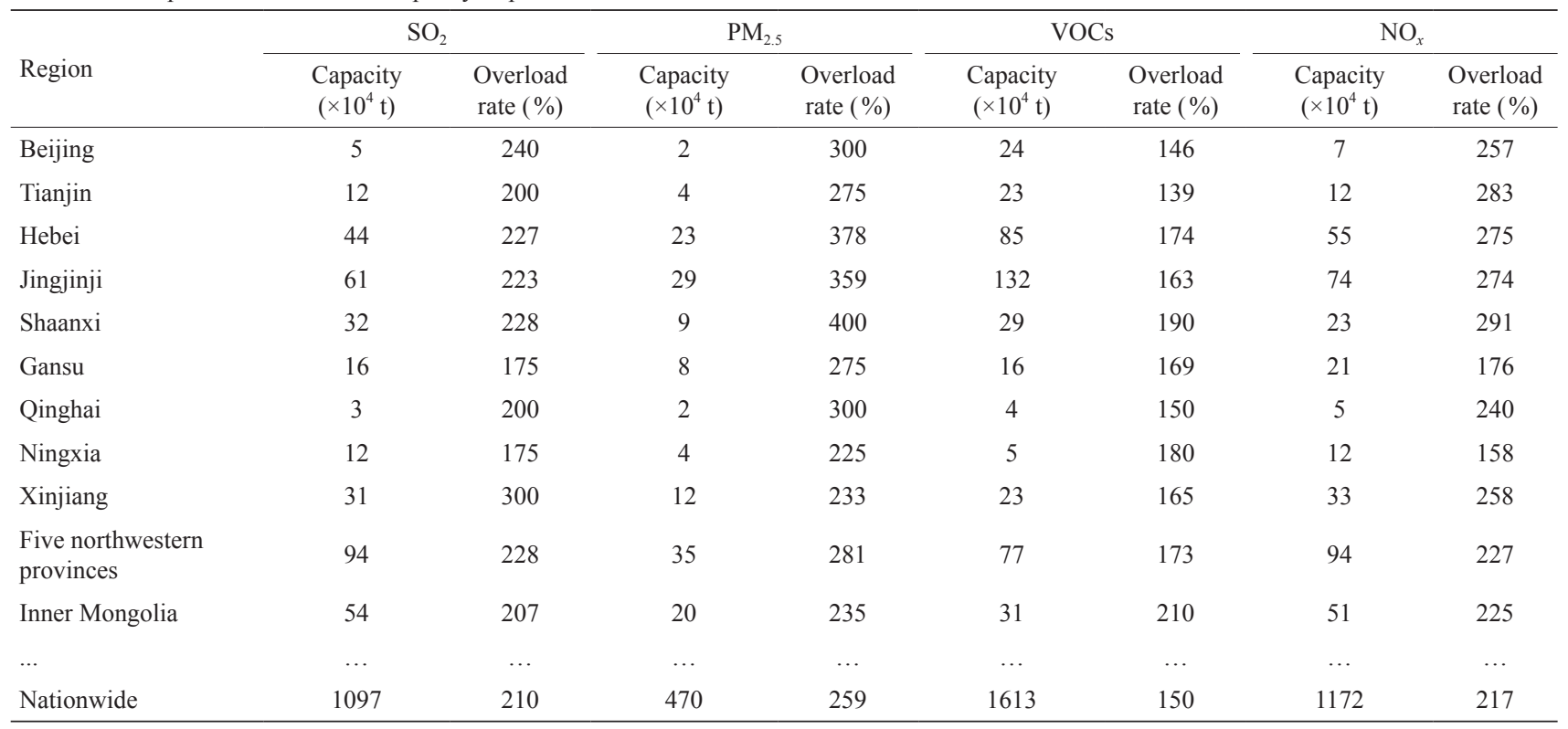


the country and in key regions were calculated and obtained, and water environmental capacity at different levels, such as control unit, control zone, and basin, were summarized. The ratio between water pollutant emissions and environmental capacity (water environment overload rate) was calculated to measure the water environmental carrying capacity status. It should be noted that the data were affected by factors such as complexity of data limitations, model selection differences, and uncertainty of parameter selection; thus, the, calculation results of water environmental capacity given herein are subject to uncertainties, and there is a need to quantitatively study such uncertainties in future studies.

The calculated results of the water environmental capacity of ten basins nationwide are shown in Table 2. Overload rates of nationwide surface water COD and ammonia nitrogen were $210 \%$ and $330 \%$, respectively. The overload in the Haihe River Basin was the most serious, with overload rates of COD and ammonia nitrogen of $1910 \%$ and $3070 \%$, respectively; the next most serious was the Huaihe River Basin, with overload rates of COD and ammonia nitrogen of $1120 \%$ and $1800 \%$, respectively. Overload rates of COD and ammonia nitrogen in the Jingjinji region were $150 \%$ and $440 \%$, respectively. The preferred development zone within the Jingjinji region core control area, the middle and south of the Hebei Province, and the key development zone within the Hengshui control zone were subject to serious overload. Overload rates of COD and ammonia nitrogen in the five northwestern provinces and Inner Mongolia were 38\% and $87 \%$, respectively, and the overloaded areas were mainly concentrated in key development zones, such as the Yellow River development zone.

\subsection{Water resource carrying capacity}

Ten representative indicators were selected from water resources and their development and utilization, regional economic development, and ecological and water environment status. An evaluation model of the comprehensive coordination degree of water resources was established, and the comprehensive coordination degree of water resources nationwide and in ten basins in 2013, coordination degree of water resources and economic and social development, and coordination degree of water resources and ecological environment protection were calculated and analyzed to represent the water environmental carrying capacity status. The ratio between water demand and available water supply (water resource overload rate) was calculated to measure the water resource carrying capacity status of the jingjinji region and western region.

The evaluation and analysis of the comprehensive coordination degree of nationwide water resources and the regional economy showed that the water resource carrying capacity of the southern region was overall superior to that of the northern region, and the water resource carrying capacities of North China and Northwest China were the worst. In terms of river basins, water resource carrying capacities of the Liaohe River Basin, Yellow River Basin, and Haihe River Basin were the worst, and the coordination degrees of water and the social economy of most regions were classified as "extreme mismatching." Basins of rivers in northwest China, the Huaihe River Basin, and Songhua River Basin were in second place with most coordination degrees classified as "basic matching" and "mismatching." Some areas were even classified as "extreme mismatching." The Yangtze River Basin, basins of rivers in southwest China, basins of rivers in southeast China, and the Pearl River Basin had strong water resource carrying capacities, and the coordination degrees of most areas were classified as "matching" or "perfect matching."

In terms of the water resource carrying capacity of the Jingjinji region, the degree of development and utilization of water

Table 2. Water environmental capacity of pollutants and overload status.

\begin{tabular}{|c|c|c|c|c|c|c|}
\hline \multirow[b]{2}{*}{ River basin } & \multicolumn{3}{|c|}{ COD } & \multicolumn{3}{|c|}{ Ammonia nitrogen } \\
\hline & $\begin{array}{l}\text { Capacity } \\
\left(\times 10^{4} \mathrm{t}\right)\end{array}$ & $\begin{array}{c}\text { Emissions } \\
\left(\times 10^{4} \mathrm{t}\right)\end{array}$ & $\begin{array}{c}\text { Overload rate } \\
(\%)\end{array}$ & $\begin{array}{l}\text { Capacity } \\
\left(\times 10^{4} \mathrm{t}\right)\end{array}$ & $\begin{array}{c}\text { Emissions } \\
\left(\times 10^{4} \mathrm{t}\right)\end{array}$ & $\begin{array}{c}\text { Overload rate } \\
(\%)\end{array}$ \\
\hline Songhua River Basin & 90 & 219 & 240 & 6.1 & 13.3 & 220 \\
\hline Liaohe River Basin & 34 & 159 & 470 & 1.8 & 12.5 & 700 \\
\hline Haihe River Basin & 13 & 248 & 1910 & 0.7 & 21.5 & 3070 \\
\hline Huaihe River Basin & 29 & 325 & 1120 & 1.9 & 34.2 & 1800 \\
\hline Yellow River Basin & 114 & 174 & 150 & 5.2 & 17.4 & 330 \\
\hline Yangtze River Basin & 370 & 622 & 170 & 37.8 & 78.2 & 210 \\
\hline Taihu Lake Basin & 46 & 31 & 70 & 2.5 & 4.9 & 200 \\
\hline Pearl River Basin & 231 & 287 & 120 & 8.2 & 34.1 & 420 \\
\hline Basins of rivers in Southeast China & 120 & 117 & 100 & 5.7 & 16.4 & 290 \\
\hline Basins of rivers in Southwest China & 15 & 31 & 200 & 1.1 & 2.6 & 230 \\
\hline Basins of rivers in Northwest China & 25 & 97 & 390 & 0.8 & 6.5 & 820 \\
\hline Nationwide & 1086 & 2278 & 210 & 71.9 & 236.8 & 330 \\
\hline
\end{tabular}


resources in the Jingjinji region exceeds $100 \%$, and water resources are under serious overload. Analysis results of future supply and demand showed that under the condition of a median water year, available water supply for the Jingjinji region in 2020 will be about $2.889 \times 10^{10} \mathrm{~m}^{3}$, the water demand will reach $3.035 \times 10^{10} \mathrm{~m}^{3}$, and the water shortage will be about $1.46 \times 10^{9} \mathrm{~m}^{3}$. The available water supply for the Jingjinji region in 2030 will be about $3.029 \times 10^{10} \mathrm{~m}^{3}$, the water demand will reach $3.171 \times 10^{10} \mathrm{~m}^{3}$, and the water shortage will be about $1.42 \times 10^{9} \mathrm{~m}^{3}$.

Insufficiencies mainly lie in urban domestic water and industrial grid demand in the Hebei Province. As for the supporting capacity of five coal-fired power bases in the western region, all five coal-fired power bases are located in arid or semiarid areas. Coal-fired power, as an industry subject to high water consumption, is extremely restricted by the conditions of water resources. Water consumption of the five coal-fired power bases is mainly agricultural water, the proportion of which currently exceeds $80 \%$. In addition, agricultural water using ecological water is very common. The proportion of industrial water use in northern Shaanxi and Erdos is relatively high, and needs particular attention. The analysis of supply and demand of future water resources against coal-fired power development showed that the increase in available water supply for the five coal-fired power bases in the western region in 2030 will be about $3.06 \times 10^{9} \mathrm{~m}^{3}$, the new water demand of coal-fired power development will be about $8.47 \times 10^{8} \mathrm{~m}^{3}$ as per the limit standard, and new water volume will be about $5.12 \times 10^{8} \mathrm{~m}^{3}$ as per the water-saving advanced value. Regardless of the limit value or the advanced value, the proportion of increase in available water supply far exceeds the current proportion of water consumption of the coal-fired power industry.

\section{National industry and energy layout strategy within the constraints of environmental carrying capacity}

\subsection{Industry and agriculture}

3.1.1 Renovating high-energy-consumption, heavy-pollution, and low-efficiency industries

The calculations of both atmospheric environmental capacity and water environmental capacity indicated that the overload rate of eastern regions was clearly higher than that of the western region, and the water resource carrying capacity of the northwest region was relatively low. The high proportion of heavily polluting industries in the eastern region is an important reason for the high environment overload rate in the eastern region. Therefore, new capacities of high-energy-consumption and heavy-pollution industries should be strictly controlled, and elimination of outdated capacities of key industries, such as iron and steel, cement, electrolytic aluminum, and sheet glass, should be conducted. Along the banks of seven key basins, the environmental risks from petroleum processing, chemical materials and products manufacturing, pharmaceutical manufacturing, chemical fiber manufacturing, nonferrous metal metallurgy, textile dyeing, and other projects should be controlled. Facilities such as production plants and dangerous chemical warehouses should be reasonably arranged. The existing steel and iron, nonferrous, papermaking, dyeing, bulk pharmaceutical chemical manufacturing, chemical industry enterprises, and other polluting and contaminating enterprises in urban built-up areas should be removed from such areas or closed according to laws [8].

3.1.2 Strengthening industrial restructuring and management of special pollution emission limits

For areas with environmental capacity utilization ratios of less than $50 \%$, efforts should be made to moderately develop industries with local advantages under the conditions of meeting industrial emission standards. For areas with environmental capacity utilization ratios of between $80 \%$ and $100 \%$, it is necessary to give early warning and to develop the industrial restructuring guiding scheme or industrial emission standard schemes to reserve space for follow-up development. In the meantime, we should encourage the development of projects, such as information networks, state grids, national oil and gas pipelines, ecological environment protection, clean energy, sea, land, and air transportation, oil and gas and mineral resource guarantees, development of information logistics and warehousing industries, advanced technical equipment manufacturing, computer software, hardware, and service industries, development of watersaving and efficient modern agriculture, low-water-consumption high-tech industries, and ecological tourism. We should use industrial emission standards to propel industrial technology progress and greenization levels. For preferred development zones and key development zones, ultra-low industrial emission standards should be promoted, which should adjust the emission standard of ammonia nitrogen in wastewater directly discharged into natural water to $1.5 \mathrm{mg} \cdot \mathrm{L}^{-1}$. For main producing areas of agricultural products and key ecological preservation areas, we should focus on improving the pollutant emission standards for livestock breeding.

3.1.3 Water resource carrying capacity and water resource efficiency should be taken into consideration for agricultural distribution

Agricultural water resource allocation and distribution is a critical problem of water resource allocation in China. Agricultural distribution should be based on the premise of matching husbandry and land and water resources. The main allocation of agricultural water resources should concentrate on adjusting the agricultural structure, transforming the agricultural growth mode, adjusting the plantation structure, improving the water productive efficiency, and promoting biological water saving strategies. 


\subsection{Coal development and utilization}

3.2.1 Strengthening the construction of water resources and water systems in western regions and guaranteeing the coal production capacity in western regions

According to the carrying capacity constraints of water resources and ecological environments in the western region, we should focus on constructing a batch of large and extra-large mine groups, and give priority to construction of superior-quality thermal coal mines, extra-large modernized open coal mines, coalfired power, and coal conversion integrated projects. Coal resource development in central and western regions should be guaranteed in terms of water rights allocation, and support should be given in terms of water policy. While strengthening construction of water resources and water systems in coal resource development zones in central and western regions, we should improve laws and standards for water management, water consumption, and water saving in mining areas (especially those in the northwest region), regulate the water intake and consumption behaviors in mining areas, develop strict entry conditions considering aspects such as water resource protection, water resource allocation, mine water treatment, and comprehensive utilization, and encourage the increase in water consumption via water right replacement.

3.2.2 Developing green mining technology and equipment to advance the scientific development of coal in the northwestern region

Customized technologies and equipment should be developed in all main production areas of coal according to the main restriction factor of scientific development, with emphasis being placed on green mining technologies and equipment for the development of water-preserved mining, mining with filling, and governance of the surface depression area, among others. Moreover, we should advance the scientific development of the key areas in the five provinces and autonomous regions in northwest China, give priority to the development of areas abundant in coal, give overall consideration to factors such as coal resources, water resources, environmental conditions, and regional economic development, and strengthen the construction of the coal industrial base. We should make overall arrangements for the production of coal in a scientific and reasonable way according to the capacity of the environment, such as the water and air in each region, conditions of resource reservations, and status and trends of industrial and social development, to realize the goal of transforming "gearing production to demand" into "gearing production to environmental capacity."

3.2.3 The modern coal industry should be developed in accordance with the coal capacity by following the principle of giving priority to environmental protection and seeking green and sustainable development

The development of the modern coal chemical industry can partially substitute the consumption quantity of petroleum and natural gas in China, thereby promoting the diversification of raw materials in the petrochemical industry, providing strategic support for national energy security and providing emergency support for petroleum security. As for the development of the coal chemical industry, project construction must be conducted in the regions where water resource conditions permit, and the development scale of the modern coal chemical industry should be planned rationally according to the analysis and potential change in the amount of available water supply. Strict environmental protection standards should be followed. If the area lacks a pollutant-holding water body or the pollutant-holding water body cannot receive the discharged wastes, a red line for restriction on receiving of pollution should be implemented in the water function area to realize full recycling of wastewater; the standard of up-to-standard discharge of wastewater must be implemented strictly when it meets the requirements of the pollutant-holding water body. We should arrange pilot projects in a scientific and reasonable manner by giving overall consideration to the resource conditions, environmental capacity, ecological safety, transportation, and product market, and arrange the resource development scale and industrial layout based on the bearing capacity of the resource environment according to the energy guarantee, transportation, and processing capacity, so as to promote regionalized and base-oriented sustainable development [9].

3.2.4 Reducing the total quantity of coal in the region, implementing the policy of equal amount replacement for coal consumption, and strictly controlling the emissions limits of pollutants

First, the total quantity of coal consumed should be controlled. The maximum allowable quantity of coal consumption should be controlled under pollution control and energy efficiency levels to achieve air quality goals, to control the total amount of pollutants, and to achieve energy saving targets. Second, the goal consumption layout should be optimized. The regional distribution of coal consumption and distribution of industries that are major coal consumers should be restricted and controlled based on the spatial difference in pollutant diffusion, release, and self-cleaning capacity, so as to guide the spatial layout of coal consuming industries effectively in order to meet the requirements of air quality limits. Third, the coal consumption structure should be adjusted. Considering the difference between the coal utilization efficiency, pollutant emission control level, and supervision conditions of different industries, the distribution of total coal consumption among different industries should be adjusted. Fourth, the coal utilization level should be improved. The coal consumption intensity and pollutant emissions intensity of the coal of products of the producers should be reduced by improving coal combustion technology, managing levels of pollutant emissions and controlling technology. 


\section{Strategy for industrial development layout of key areas within the constraints of environmental carrying capacity}

\subsection{Jingjinji region}

(1) Based on the constraints of the atmospheric environmental capacity: on the industrial aspect, efforts should be made to achieve overall optimization and adjustment, to encourage and recommend the use of natural gas and electricity to implement emission reduction (through technologies) measures, and to control the quantity of products with high pollution. The measures for promoting emissions reduction, control, and adjustment should be implemented to improve the process technology of steel, cement, glass, and nonmetal industries to gradually reduce the production capacity. Emphasis should be placed on the development of new energy industries, including solar energy and bioenergy, to develop new intelligent equipment manufacturing and foster electronic information, biological pharmacy, and new materials. On the civil aspect, it is necessary to strengthen infrastructure construction for civil energy, improve civil infrastructures, increase the difficulty in utilizing energy sources which cause high rates of pollution, such as coal, and increase the utilization and supply of coal gas and natural gas. On the transportation aspect, we should encourage the utilization of new energy automobiles, strictly control the number of vehicles, and supervise the allocation of equipment for reducing the tail gas of vehicles so as to improve the quality of gasoline and diesel. On the power generation aspect, we should encourage reduction in emissions of air pollutants from thermal power plants and should not increase the number and size of large thermal power plants. On the aspect of heat supply, we should improve the technology used in heat supply equipment to reduce air pollutants, and increase the number of centralized heating plants that consume natural gas.

(2) Based on the constraints of the water environmental capacity: the policy for shutting down or transferring entire industries should be adopted for textile printing and dyeing, leather, and papermaking industries (the COD is approximately 49-66 t/100 million yuan and ammonia nitrogen discharge is approximately 2.2-4.9 t/100 million yuan), according to the standards of pollutant discharge per 100 million yuan GDP. The same policy should also be adopted for the chemical, food, and pharmaceutical industries (the COD is approximately 10-15 t/100 million yuan and ammonia nitrogen discharge amount is approximately 1-2 t/100 million yuan), or measures of clean production and transformation and improvement of wastewater processes can be adopted. In particular, the development trend of clean production and transformation and improvement of wastewater treatment processes should be implemented for the pharmaceutical industry, which accounts for only $16 \%$ of the wastewater discharged to surface water.
(3) Based on the constraints of water resources: the Jinginji region can be generally divided into levels according to water utilization efficiency, the first is Beijing and Tianjin, where overall water resource utilization efficiency reaches or approaches the levels of developed countries. The Hebei Province ranks second, where the overall water resource utilization efficiency is not high. Industrial restructuring is required in the Hebei Province to realize the sustainable development of water resources and the economy. (1) Strong efforts should be made in the development of tertiary industries; adjustment and improvements should be made in secondary industries and restrictions should be implemented on primary industries. (2) Plantation structure should be adjusted for agriculture in order to develop dry farming and to improve the general system of yielding two crops each year (including the winter wheat and summer maize) to a system of yielding one crop each year (including maize, cotton, peanuts, sunflower oil, and coarse cereals). The development of crops such as silage corn and alfalfa should be supported according to the development of animal husbandry. (3) The development of emerging technology-intensive industries, such as electronic information and electrification, should be supported. The development of the traditional petrochemical industry and metallurgical industry should be restricted. (4) The development of industries inside the tertiary industries should not be restricted, instead their development towards an advanced level should be promoted; thereby, facilitating a transformation from traditional service industries, such as retail and catering, to highly intellectual modern service industries and communication industries, such as finance, insurance, and scientific research industries.

\subsection{Five northwestern provinces and Inner Mongolia}

(1) Based on the constraints of the atmospheric environmental capacity: according to the emissions capacity of air pollutants and the characteristics of having vast territories with sparse populations in the five northwestern provinces and Inner Mongolia, efforts should be made to make full use of local natural gas to improve the energy structure. The enterprise should be supervised to increase emissions reduction equipment and limit the quantity of products with high-energy consumption and low yield. For the cement industry, which causes severe pollution in this area, strict measures to improve the process and reduce productivity should be implemented. For the coal chemical industry and coking industry, among others, which give rise to serious pollution, the process of the coal chemical industry should be slowly advanced, and the output of coal coking plants should be strictly controlled. On the civil aspect, measures such as reducing the price of civil emission-reduction coal-fired equipment and provision of allowances should be implemented to reduce the emissions of coal combustion and to gradually increase the proportion of coal gas and natural gas. On the transportation aspect, national and local standards regarding fuel vehicles should 
be strictly implemented, and the use of gas-fueled vehicles and new energy vehicles should be popularized. On the power generation aspect, technical transformation should be conducted for old and outdated thermal power plants in order to control the scale and quantity of thermal power plants. Natural gas power plants should be increased in the areas abundant in natural gas to transfer electricity outwards. The number of solar power plants and wind power plants should be increased to reduce the pressure of outward transfer and supply of power. On the aspect of heat supply, technical transformation should be conducted for heat supply equipment, the number of natural gas heat supply plants should be increased, and heat collection using solar energy and geothermal energy, among others, should be encouraged.

(2) Based on the constraints of the surface water environmental capacity: a reasonable layout should be implemented according to the utilization degree of the environmental capacity of the surface water in the five northwestern provinces and Inner Mongolia. Major industries that discharge pollutants include the metal smelting, mining, petrochemical, chemical, food and papermaking industry, which account for $73 \%$ of the value of gross output. The emission of COD accounts for $92 \%$ of the total amount in this area, and the emission of ammonia nitrogen accounts for $95 \%$ of the total amount in this area. A policy to shut down or transfer the entire industry should be adopted for the chemical, food, and papermaking industries according to the standards on pollutant discharge per 100 million yuan GDP. Measures such as regionalized clean production, transformation, and wastewater treatment can be implemented for the metal smelting industry and the petrochemical industry in areas where there is surplus environmental capacity. The development of economic industries that meet the requirements of major functional planning can be advanced in key ecological preservation areas to realize faster economic development under the premise that there is no ecological environmental destruction.

(3) Based on the constraints of the water resource carrying capacity: the constraints are mainly on the water resources in the northwest region, and mainly on the water used for agriculture. The utilization of water for agriculture should be popularized, and its scale should be compressed to ensure a supply of ecological water and industrial water consumption. Water-saving technology should be adopted for moderate development of the industry. The scale of water used for agriculture should be compressed, and comprehensive water conservation techniques for the agriculture transfer of water right on a paid basis and for highly efficient water use for the industry should be implemented to support the development of a coal-fired power base in the northwest region and to ensure that the local ecological environment will not be destroyed. Special efficient and water-saving agriculture should be developed to improve water-use efficiency. The unlimited sprawl of irrigation areas should be strictly controlled to convert the water saved in agriculture to industrial applications to guarantee industrial development. The industrial water in the north of the Shaanxi Province and the Ordos City uses a higher proportion. An industrial structure optimization is required in the future; industries with high water consumption, other than the energy industry, should be transferred. The development of the energy industry should be strictly controlled. Meanwhile, water-saving techniques in the energy industry should be further intensified, and advanced water-using techniques should be actively adopted.

\section{Conclusions}

Ecological civilization construction must meet the requirements of sustainable management in national land areas, especially in main functional areas and in ecological environment areas. At present, the environmental carrying capacity is the main bottleneck for a sustainable development of China's society and economy. As an important aspect of economic development, the industrial layout is also restricted by the environmental carrying capacity, which determines the type of industries and the industrial layout in a region. The evaluation of the environmental carrying capacity was conducted throughout the country, in the Jingjinji region, in the five northwestern provinces, and in Inner Mongolia from the aspects of atmospheric environmental capacity, water environmental capacity, and water resource carrying capacity. Strategies for the green layout of industries nationwide and energy resources in key areas were proposed tentatively. These are of significance for guiding the transformation of economic development nationwide and in key areas, for optimization of the pattern of development of national land, and for promotion of sustainable development.

\section{Acknowledgments}

This article is one of the core contents of Subject II of the Chinese Academy of Engineering Advisory Project "Several Strategic Issues on Eco-Civilization Construction (Phase II)." I would like to extend my thanks to all the main experts participating in the research of this subject: Wang Hao, Li Yang, Qu Jiuhui, Li Zheng, Cheng Yibu, Shan Baoqing, Xu Jiayu, Ma Jing, Chu Junying, Li Weiqi, Wen Shengfang, Deng Wei, Wu Jian, etc.

\section{References}

[1] Fan J, Wang Y F, Tang Q, et al. Academic thought and technical progress of monitoring and early-warning of the national resources and environment carrying capacity (V 2014) [J]. Scientia Geographica Sinica, 2015, 35(1): 1-10. Chinese.

[2] Yuan G H, Zheng J E, Jia L B, et al. Evaluation monitoring and the idea of warning concerning carrying capacity on resource and environment [J]. Natural Resource Economics of China, 2014(4): 20-24. Chinese.

[3] Wang W, Jiang Y, Zhang L B, et al. Study on Chengdu industrial spatial distribution based on ecological carrying capacity [J]. Re- 
search of Environmental Sciences, 2010, 23(3): 333-339. Chinese.

[4] Wu N, Fu Z Q, Xie Y Y et al. Review on the research progress of industrial layout optimization based on ecological carrying capacity [J]. Ecological Economy, 2015, 31(5): 21-25. Chinese.

[5] Chen D, Wang R. Resource \& environment carrying capacity situation assessment and policy recommendations $[\mathrm{J}]$. Ecological Economy, 2015, 31(12): 111-124. Chinese.

[6] Xue W B, Fu F, Wang J N, et al. Modeling study on atmospheric environmental capacity of major pollutants constrained by PM2.5 compliance of Chinese cities[J]. China Environmental Science, 2014, 34(10): 2490-2496. Chinese.
[7] Zhou G, Lei K, Fu G, et al. Calculation method of river water environmental capacity [J]. Journal of Hydraulic Engineering, 2014, 45(2): 227-242. Chinese.

[8] The State Council of the PRC. Circular on the issuance of action plans for water pollution control by the State Council of the PRC [EB/OL]. (2015-04-02) [2017-03-29]. http://www.gov.cn/zhengce/ content/2015-04/16/content_9613.htm. Chinese.

[9] China Petroleum Chemical Industry Federation. Modern coal chemical industry "13th Five-Year" development guide [EB/OL] (2016-04-06) [2017-03-31]. http://www.coalchem.org.cn/dujia/ html/800214/173156.html. Chinese. 